\title{
The Application of Prefabricated Chunks Theory to English Teaching in Newly-built Private Colleges
}

\author{
Xiufang Wang \\ Nanchang Institute of Science \& Technology, Nanchang, 330108
}

\begin{abstract}
There is little room for students in newly-built private colleges to improve their English due to various reasons. But private colleges, in particular, require fostering application-oriented talents, which is a big challenge for both students and teachers. The chunk combines the form, meaning of a language with its context and it can be stored and extracted as a whole in the acquisition process, which will undoubtedly enhance the accuracy and fluency of language use. Thereby it is one of the effective ways for students in private colleges to learn English and develop competence of language use.

Keywords: Prefabricated Chunk Theory; Newly-Built Private Colleges; College English Teaching
\end{abstract}

\section{An Introduction to Chunk Theory}

As a method of second language acquisition, chunk theory emerges with the rise of cognitive linguistics and corpus linguistics. In addition to words of free combination with linguistic rules and fixed phrases that can not explained by rules, there are many semi-fixed structures which has characteristics of both vocabulary and syntax. The combination is not very fixed, but the form is relatively fixed, such as tens of, hundreds of, thousands of and millions of and so on. These phrases are often stored and used as a whole because of their frequency or effectiveness. This fixed or semi-fixed multi-word combination structure is called formulaic sequence. Wray points out that a chunk is a string of 
prefabricated coherent or incoherent words or other units of meaning. They are stored in the memory as a whole, extracted directly when used, without the need for syntax generation and analysis (Wray, 2002).

The concept of chunks was first proposed by Pawley \& Syder, who argue that the existence of a large number of prefabricated chunks is the key to the native like selection and fluency of speech at or near the level of the mother tongue. Therefore, chunks play a vital role in the acquisition of a language. Some scholars pointed out native speakers have been unconsciously relying on chunks in the process of communication, and this is one of the reasons why mother-tongue users are less proficient in the grammar part of their native language than L2 speakers. Therefore, in order to improve the boring and inefficient state of second language learners' learning of L2 grammar, second language acquisition researchers have begun to try to regard the ability of language learning and teaching as an important indicator, and carry out teaching reform based on chunk in the college English classroom. Bishop and other researchers found that second language learners often fail to identify the chunk due to lack of natural language environment so that teaching intervention must be adopted to promote the acquisition of chunks.

More than 10 years ago, chunk theory began to be recognized in China. Most studies take it as the theoretical framework for college English teaching reform. For instance, when learning from English textual recitation at the initial stage of English study, learners can fluently recite an entire paragraph, who, in fact, has extracted one of the chunk units.

\section{Particularity of English Studying and Teaching for New Private Colleges}

English learning and teaching in new private colleges have their own characteristics:

a. Enrollment score for newly-built private colleges is lower; correspondingly, English foundation of the students is poorer. Some students' English level has dropped off in their high school, resulting in a cycle of decrease, and ultimately they lost confidence in English learning. Even if a better basis is only reflected in the basic knowledge while the ability to use language does not fully meet the requirements of the times.

b. The learning atmosphere of newly-built private colleges is not strong enough, lack of guiding roles and other effective incentive mechanisms. Students simply believe that the university is a paradise, without academic constraints and the control of parents, they can play freely. Not to mention let them take the initiative to remember the words and recite texts, it's difficult to make them listen to lectures attentively. Without a strong motivation, students take a negative attitude toward their English learning.

c. Because of the lower level of faculty and less opportunities for teacher training, there is a lack of creative teaching methods. Coupled with the poorer 
teaching hardware and software equipment, make the progress in students' English learning slower.

\section{Advantages for Teaching Based on Chunk Theory}

In the traditional context of English teaching, Chinglish is the distinguished problem when use English. No matter in the process of translating, writing or oral expression, they usually think in Chinese first, and then put a couple of isolated words together into the corresponding English. But the thinking differences between Chinese and Westerners make it no absolute correspondence in both languages. Because the chunk is a fixed or semi-fixed multi-word combination, which can be directly extracted to use in many cases, when it is used, the language will be more authentic and accurate.

Once chunks are kept in the mind, they can be directly extracted for use. Compared with temporary-combined sentences, chunks are more helpful for English users to express their ideas.

Idioms and collocations are similar to chunks in form, but do not have pragmatic functions. There are three pragmatic functions of the chunk, namely, "social interactions", "necessary topics" and "discourse devices". Each of these three pragmatic functions contains many specific pragmatic functions. Chunks are stored in the brain in the form of semantic fields. Chunks of different meanings are distributed in different semantic fields, and those with the same pragmatic functions are clustered in the same semantic field. When the learners memorize and store enough chunks, they can extract the most suitable ones according to the communicative scenes to express themselves appropriately.

Language output is the best way to test the effectiveness of language learning. But even an English learner with large vocabulary, good reading and listening comprehension ability, high scores in CET 4 and CET 6 are usually unable to output language naturally and fluently. Learners' confidence can be multiplied and learning outcomes be improved by borrowing prefabricated chunks of formulaic formulas that are stored in the brain as a whole to make verbal or written output fluent.

Chunk learning does not rely on students' English foundation, just an extensive learning for students with a command of words. As long as students are willing to memorize and follow rules, it is helpful for them to enhance the practical capacity, and therefore very suitable for students of lower English starting points in the new private colleges.

\section{Application of Chunk Theory}

Language learning usually involves two alternating cycles of input and output. Then this paper will start from these two aspects to study the application of chunk theory into college English teaching. 
First of all, to cultivate chunk awareness in the course of language input, taking chunks as the unit of vocabulary acquisition. For instance, as a single word, "have" means "with...", but it has rich meanings in different chunks. In "have breakfast", it means "eat"; in "have a meeting", it means "hold"; in "have a fever", it stands for "suffer" while in "have a cold", it means "catch". Taking chunks as a whole memory unit can not only form a more comprehensive understanding of the usage of a word, but also convey a more authentic expression of ideas, avoiding the phenomenon of Chinglish.

Besides, long sentences are often one of the factors that affect students' understanding of discourse. And long sentences usually contain many lexical chunks, so when analyzing them, we should consciously develop students' ability in chunk recognition. For example, in the sentence "Even after Emperor Claudius passed his law, I kept on performing marriage ceremonies-secretly." there appear chunks as "even after ...", "pass his law", "keep on doing" and "perform marriage ceremonies". In the process of teaching, teachers can train students' competence of finding chunks by assigning tasks of blank filling and other modes.

Last but not least, because the chunk itself has semantic, pragmatic and grammatical characteristics, it is more comprehensive, deeper and more effective to understand the discourse through chunks rather than independent words. Take a piece of CET4 exercise as an example: "In a mind of Westerners, Chinese people have the closet connection to rice, basic food for the Chinese. For a long time, rice occupies a very important position in the Chinese diet. ..." In the short paragraph, there are a great amount of chunks. If let the students read literally, either the difficult words will hinder understanding or the whole text will be incoherent. When taking the chunk as a unit, the article is not too fragmented so that the students can read and understand the main ideas in one go.

The output of a language mainly consists of the oral and written aspects, which is still the biggest difficulty for the second language learners, especially for students in newly-built private colleges. But to develop the capacity of language output happens to be the outstanding requirements of current application-oriented colleges.

Structure is usually considered as a critical point of writing a good article, and the understanding of chunks can help the learners to better grasp the overall framework of an article. In CET-4 and CET-6, learners can flexibly express their views in the beginning of a picture easy as "the picture presented to us...", "the cartoon reveals an astonishing scenario..., "the picture above features a parachute in the air...", "the picture shows us a dialogue ..."; in the developing part, chunks like "this picture highlights the importance of ...", "admittedly, the internet is of great use in settling certain problems...", "in fact, the picture reminds us of the importance of policy morality..."; and in the concluding section, to adopt chunks as " judging from what have been discussed above...", "as far as I am concerned...", "to sum up...", "all in all...". These chunks help construct a logical composition with a clear structure, good organization and coherent meaning.

Similarly, input a large number of chunks of self-introduction, addressing and other daily communications before verbal output. Then repeat imitation practice. 
And prepare writing and oral chunk tasks through the network so that the students continue accessing to them and thus master the knowledge.

\section{Inspiration and Conclusion}

In view of the effective application of chunk theory in the new private colleges, teachers should adjust their future teaching. Instead of the modes of words and sentences explanation, teachers can take discourse as a unit, asking students to find chunks in it, and then strengthen understanding through the verbal and written exercises.

Next, make students understand the importance of chunks in English learning, so that they form the consciousness of chunks and cultivate the habit of inputting English chunks from various channels, and assess the effect of chunks learning on a regular basis.

Finally, the students will be given the chance to use the chunks better by doing class English speech contest, role play, greeting, speech imitating dubbing, e-mail writing, leave writing, poster writing, etc. These activities also meet the requirement for strengthening students' practical competence in English in new private colleges.

To distinguish the chunks through classroom training and then explore the appropriate method for students to memorize a mass of chunks, aiming to make full use of them and to improve the proficiency and accuracy of English use, ultimately to improve English performance and interest in learning, which is perfectly in line with the applied personnel training requirement of the newly-built institutions.

\section{References}

[1] Wray, A. Formulaic Language and the Lexicon [M]. Cambridge: Cambridge University Press, 2002.

[2] Pawley A. \& Syder F. Two Puzzles for Linguistic Theory: Native like Selection and Native like Fluency [A] in Richards, J., Schmitt, R. (eds.). Language and Communication [C], London: Longman, 1983.

[3] Luo Yan-yan, Research on the College English Teaching of Village-origin Students form the Perspective of the Formulaic-Sequences Theory [J], Journal of Fuyang Teachers College (Social Science), 2011, 5.

[4] Luo Yan-yan, Research on the Vocabulary Teaching Model of College English Based on the Formulaic-Sequences Theory [J], Foreign Language Research, 2009, 6.

[5] Sun Wen, Research on the Teaching of Spoken English Based on the Theory of Prefabricated Chunks [J], Journal of Mudanjiang College of Education, 2011, 2.

[6] Zhao Zhi-hua, Chunk Theory- An Effective Theory for Translation Teaching[J], Journal of Qiqihar Junior Teacher's College, 2015, 4. 